\title{
T-phase formation and its effect on mechanical properties of Al-Cu-Mn alloys
}

\author{
SobanMuddassir Dar ${ }^{1}$, HengCheng Liao ${ }^{1, a}$ and GuangJing $\mathrm{Li}^{1}$ \\ ${ }^{1}$ School of Materials Science \& Engineering, Southeast University, Jiangsu Key Laboratory for Advanced Metallic Materials, Nanjing \\ 211189, China
}

\begin{abstract}
Al-Cu-Mn alloys are used in components in automotive and aircraft industry which work at high temperature. Recent research is focused on $\mathrm{Al}-\mathrm{Cu}-\mathrm{Mn}$ alloys to enhance their performance by promoting the formation of thermally stable phase particles. In this study, the effect of $\mathrm{Cu} / \mathrm{Mn}$ content on microstructure and mechanical properties of two Al-Cu-Mn alloys $(\mathrm{Cu} / \mathrm{Mn}$ wt.\% ratio $=5.56,2.75)$ is investigated by optical microscopy, scanning electron microscopy, energy dispersive spectroscopy and tensile testing. Results reveal that ascast microstructure of both the alloys consists of trunks of $\alpha$-Al dendrites surrounded by $\mathrm{Cu}$-rich interdendritic region. After solution treatment, a great amount of $\mathrm{Al}-\mathrm{Cu}-\mathrm{Mn}$ intermetallic compound particles are found to precipitate adjacent to this region. Alloy with low $\mathrm{Cu} / \mathrm{Mn}$ content ratio exhibits high strength due to relatively high amount of $\mathrm{Al}-\mathrm{Cu}-\mathrm{Mn}$ (T-phase) particles.
\end{abstract}

\section{Introduction}

Al-Cu-Mn alloys are widely used in automotive and aircraft industry due to their high strength and light weight[1]. These alloys possess excellent strength because of high density of meta-stable $\theta^{\prime \prime} / \theta^{\prime}$ precipitates after solutionizing and aging treatment. However, the service temperature of these alloys is usually limited to $250^{\circ}-300^{\circ} \mathrm{C}$ because of coarsening of these metastable precipitates[2, 3]. To improve the properties of these alloys, the effect of rare earth addition on the properties of these alloys is studied[4-6]. Recently, scientists have focused their attention in these alloys to completely avoid or suppress the formation of $\mathrm{Al}_{2} \mathrm{Cu}$ ( $\theta$-phase) and to maximize the formation of Mn-rich phase (T-phase) [7, 8]. Some of these studies have been proved to be fruitful in terms of improved properties. However, no attention is paid to microstructure evolution during/safter solidification (as-cast) and its effect on the properties. Furthermore, the solidification reactions proposed by Mondolfo[9] long ago in Al-rich portion of Al-Cu-Mn ternary phase diagram are largely of hypothetical nature and have no physical significance[10]. So, in this study, the effect of $\mathrm{Cu} / \mathrm{Mn}$ content on microstructure and mechanical property of two Al-Cu-Mn alloys is investigated.

\section{Experimental procedures}

Two alloys of varying $\mathrm{Cu}$ and $\mathrm{Mn}$ contents, as listed in Table 1, are produced from commercially pure aluminum, $\mathrm{Al}-20 \% \mathrm{Cu}$ and $\mathrm{Al}-10 \% \mathrm{Mn}$ master alloys.

\footnotetext{
a Corresponding author: hengchengliao@seu.edu.cn
}

$\mathrm{Cu} / \mathrm{Mn}$ content ratio in these alloys corresponds to 5.56(hereafter Alloy-1) and 2.75(hereafter Alloy-2), respectively. The alloys are prepared by melting at $760^{\circ} \mathrm{C}$ for $3 \mathrm{hrs}$ in an electrical resistance heating furnace. After degassing by $\mathrm{C}_{2} \mathrm{Cl}_{6}$ at $720^{\circ} \mathrm{C}$, the molten alloys are cast into a plate like cast-iron mold with a cavity of $170 \times 150 \times 20 \mathrm{~mm} 3$ which was preheated at $250^{\circ} \mathrm{C}$ for at least $5 \mathrm{~h}$. The composition of the alloys is measured by MAXx LMF15 spark emission spectrometer. The as-cast alloys are solution treated at $530^{\circ} \mathrm{C}$ for $16 \mathrm{hrs}$, then water quenched and finally aged at $170^{\circ} \mathrm{C}$ for $6 \mathrm{hrs}$. Microstructure of alloys is characterized by using optical microscopy (OM) and scanning electron microscopy (SEM). For this purpose, samples are prepared by mechanical grinding, polishing and final etching with Keller's reagent. Phase constituents are determined by energy dispersive spectroscopy (EDS). Samples for tension test are cut from the central part of casting in accordance with GB/T228-2002 (a Chinese standard). Mechanical properties are determined at $25^{\circ} \mathrm{C}$ (room temperature) and $300^{\circ} \mathrm{C}$ on a universal testing machine (CMT4503) with a strain rate of $2 \mathrm{~mm}$ min-1. For each alloy, three samples are tested at every temperature and mechanical properties are reported as an average.

Table 1: Composition of the experimental alloy by MAXx LMF15 spark emission spectrometer

\begin{tabular}{lclll}
\hline \multirow{2}{*}{$\begin{array}{l}\text { Alloy } \\
\text { Name }\end{array}$} & \multicolumn{3}{c}{ Composition, wt.\% } & \multicolumn{2}{c}{$\begin{array}{c}\mathrm{Cu} / \mathrm{Mn}, \\
\text { wt.\% ratio }\end{array}$} \\
\cline { 2 - 4 } & $\mathrm{Al}$ & $\mathrm{Cu}$ & $\mathrm{Mn}$ & \\
\hline Alloy-1 & Bal. & 1.67 & 0.29 & 5.57 \\
\hline Alloy-2 & Bal. & 2.27 & 0.77 & 2.75 \\
\hline
\end{tabular}




$$
\mathrm{Fe}<0.15 \%, \mathrm{Si}<=0.08 \%
$$

\section{Results and discussion}

\subsection{Microstructure}

Optical micrographs of as-cast alloys (Alloy-1 and Alloy2 ) are shown in Figure 1. There is no obvious difference between the microstructure of two alloys. The as-cast microstructure consists of trunks of $\alpha$-Al dendrites surrounded by $\mathrm{Cu}$-rich interdendritic region, as demonstrated in Figure 2(a), (b) for Alloy-1 and Alloy-2, respectively. Moreover, some black particles are also observed within the interdendritic region. SEM images and EDS analysis shows that these are particles of $\theta$ $\mathrm{Al}_{2} \mathrm{Cu}$ phase formed as a result of divorced eutectic reaction. In Alloy-1, the interdendritic region consists of $\alpha-\mathrm{Al}+$ globular particles of $\mathrm{Al}_{2} \mathrm{Cu}$ phase, as shown in Figure 2(a) and in Alloy-2, the interdendritic region consists of $\alpha-\mathrm{Al}+$ broken network of $\mathrm{Al}_{2} \mathrm{Cu}$ phase. Two morphologies of $\mathrm{Al}_{2} \mathrm{Cu}$ phase i.e. globular particles and elongated particles are observed in Alloy-2, as shown in Figure 3(a). It is because of relatively high amount of $\mathrm{Cu}$ present in this alloy. SEM-EDS analysis shows that in addition to non-equilibrium $\theta-\mathrm{Al}_{2} \mathrm{Cu}$ phase, some $\mathrm{Fe}$-rich and Si-rich intermetallics, formed during solidification, are also observed in the microstructure because of minor amounts of these elements present in these alloys. Distribution of alloying elements within the microstructure is studied by EDS analysis. Results reveal that most of $\mathrm{Cu}$ is present in the form of $\theta-\mathrm{Al}_{2} \mathrm{Cu}$ phase. No Mn-rich binary or ternary intermetallics are observed. It is worth noting that, in both the alloys, amount of $\mathrm{Cu}$ is low in $\mathrm{Al}$ matrix as compared to nominal composition of the alloy (Fig. 2(b) and Fig.3(b)). On the other hand, amount of $\mathrm{Cu}$ is higher in interdendritic regions (Fig.2(c) and Fig.3(c)). However, $\mathrm{Mn}$ is completely dissolved into the $\alpha$-Al matrix.
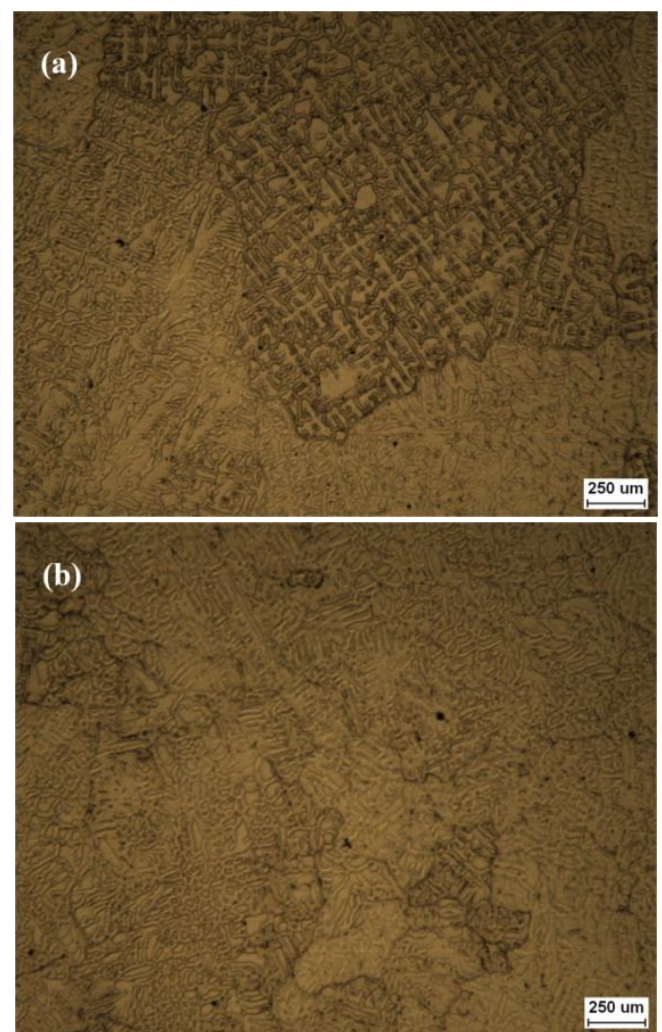

Figure 1: As-cast microstructure of prepared alloys, (a) Alloy1and (b) Alloy-2

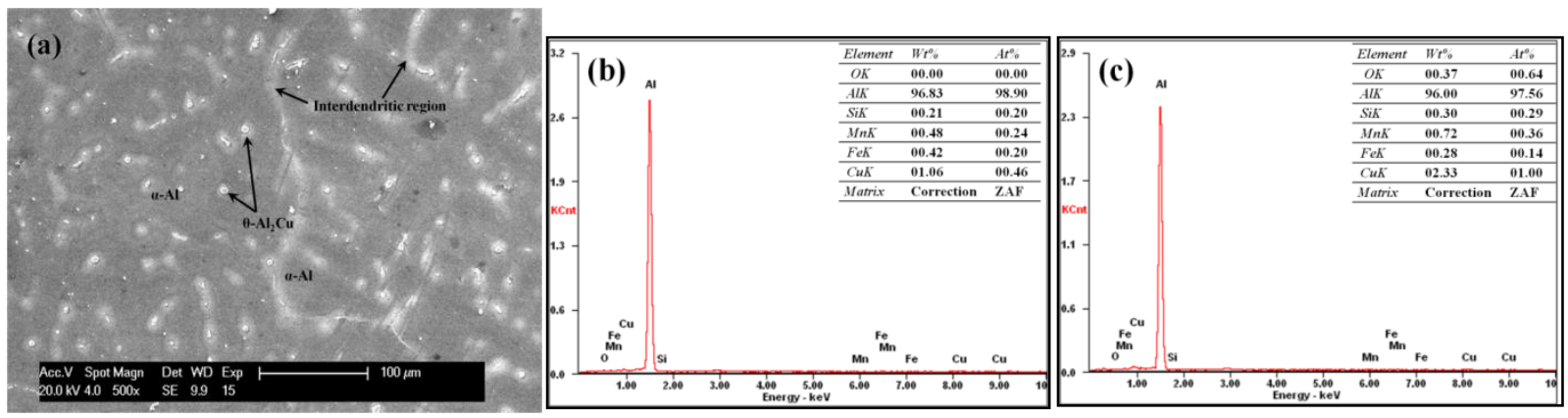

Figure 2: SEM and EDS results of Alloy-1: (a) SEM micrograph, (b) EDS analysis of $\alpha$-Al dendritic trunks, (c) EDS analysis of interdendritic $\mathrm{Cu}$-rich zone

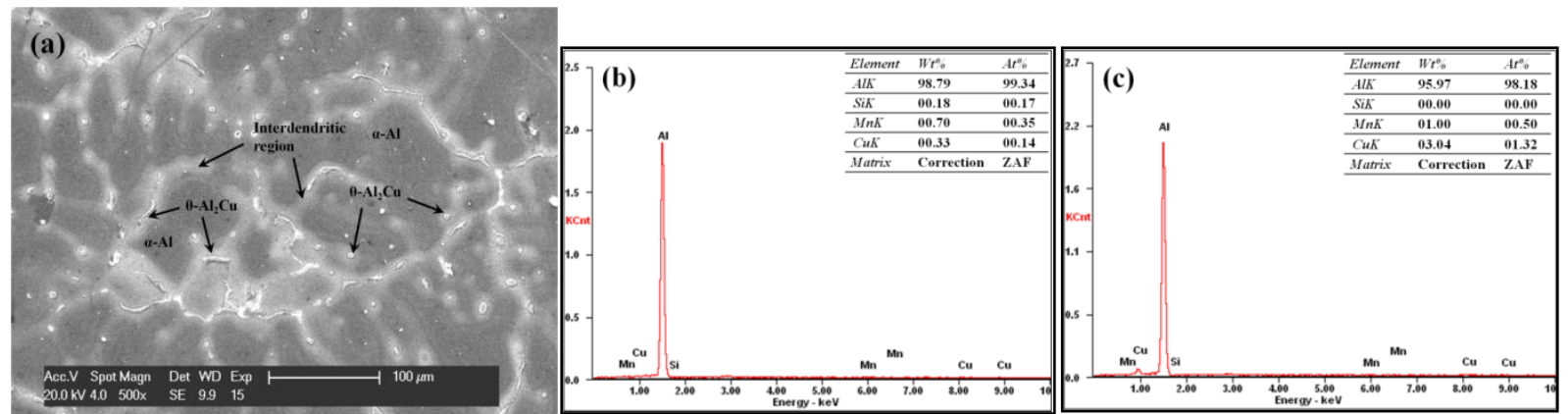

Figure 3: SEM and EDS results of Alloy-2: (a) SEM micrograph, (b) EDS analysis of $\alpha$-Al dendritic trunks, (c) EDS analysis of interdendritic $\mathrm{Cu}$-rich zone 
Optical micrographs (Figure 4) of two alloys after solution treatment $\left(530^{\circ} \mathrm{C}\right.$ for $\left.16 \mathrm{hrs}\right)$ show that there are a great amount of intermetallic particles precipitated adjacent to the interdendritic region(described in the ascast microstructure). SEM micrographs more clearly reveal it. The amount of precipitates in Alloy 2 is much greater than that in Alloy 1. In Alloy 1, most of the precipitates are thought to be $\mathrm{CuAl}_{2}$ phase due to the EDS results (Fig.5(b,c)). In Alloy 2, however, by the EDS results (Fig.6(b,c)), most of the precipitates are rod/platelike and are thought to be Mn-rich phase (T-phase). It is interestingly noted that the precipitation behavior during solutionizing occurs mostly adjacent to the interdendritic regions where it is $\mathrm{Cu}$-rich due to non-equilibrium solidification. In these regions, the $\mathrm{Cu}$ and $\mathrm{Mn}$ solutes are locally supersaturated, thus $\mathrm{CuAl}_{2}$ and/or T-Mn phases are precipitated during solutionizing.
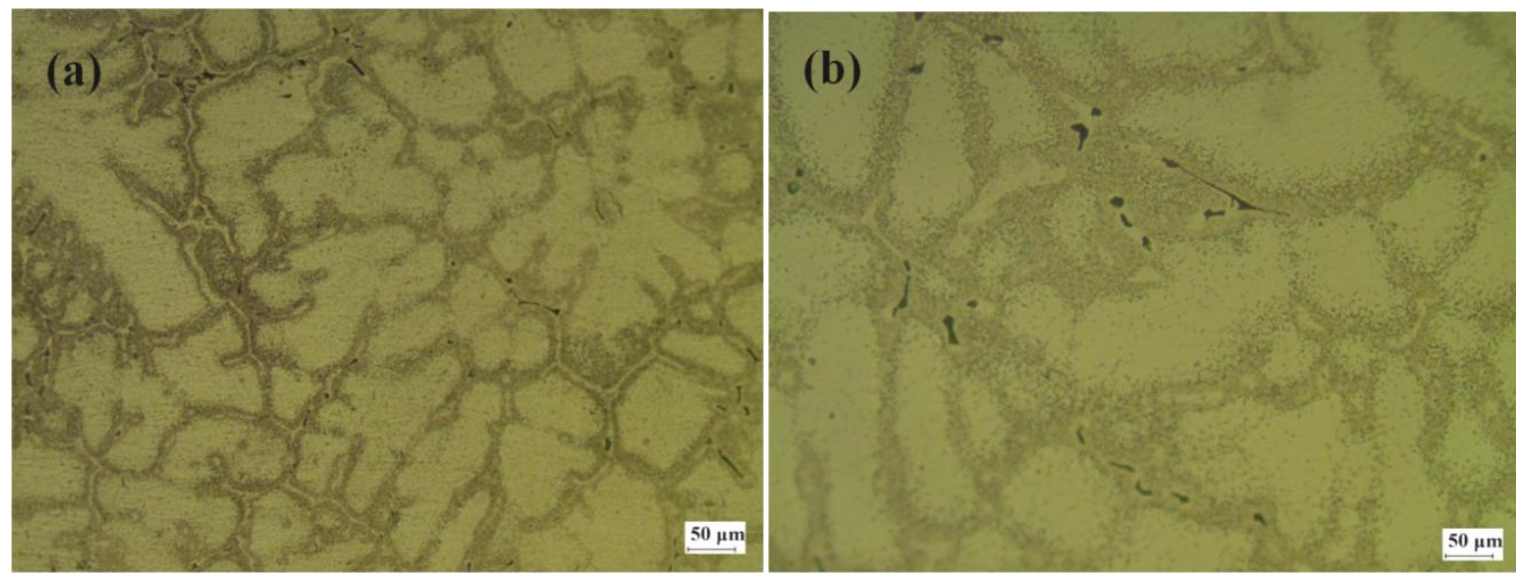

Figure 4: Optical micrographs after solution treatment $\left(530^{\circ} \mathrm{C}\right.$ for $\left.16 \mathrm{hrs}\right)$ : (a) Alloy-1, (b) Alloy-2
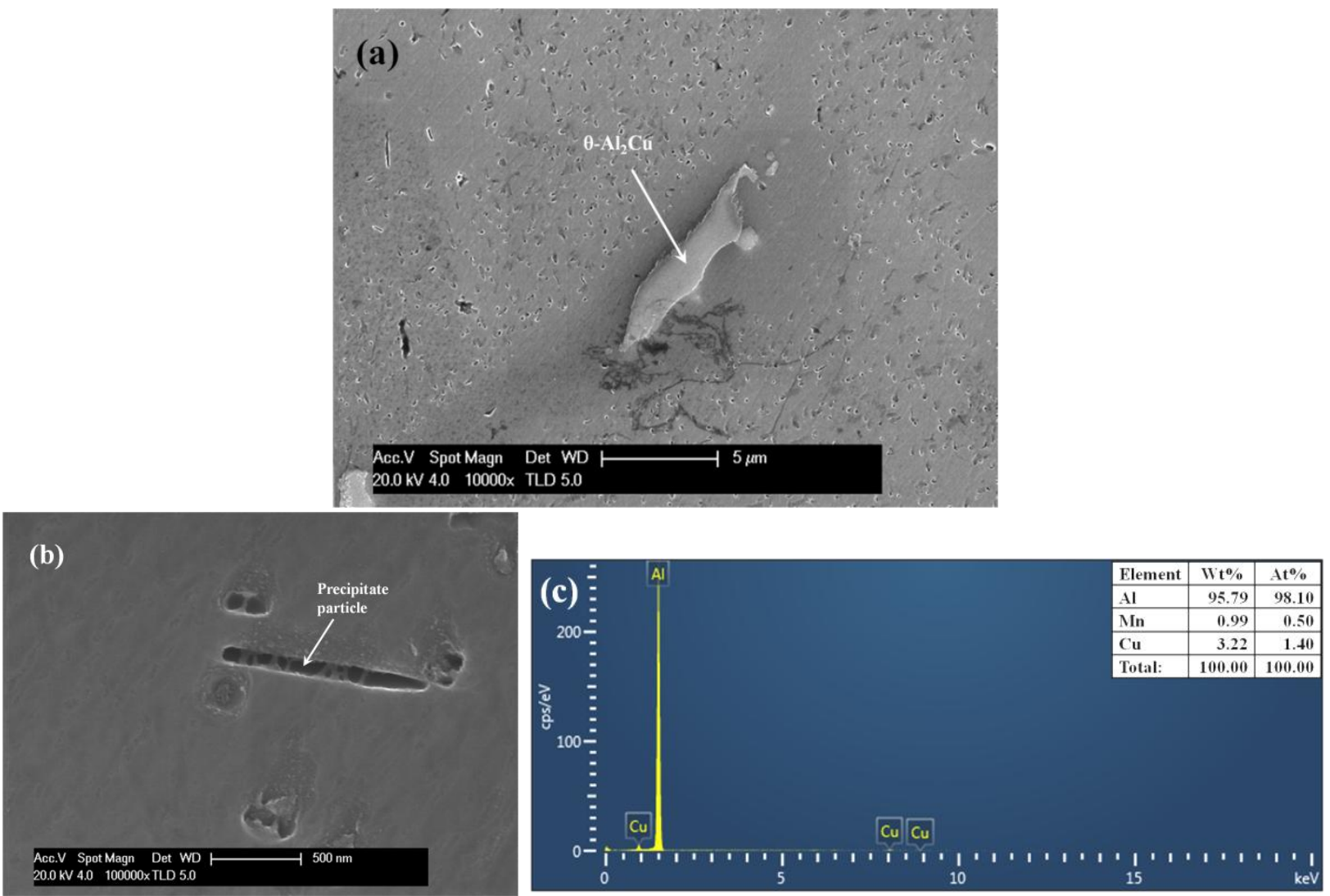

Figure 5: SEM micrographs of Alloy- 1 after solution treatment $\left(530^{\circ} \mathrm{C}\right.$ for $\left.16 \mathrm{hrs}\right)$, (a) un-dissolved $\theta-\mathrm{Al}_{2} \mathrm{Cu}$ phase and precipitate particles adjacent to interdendritic region, (b) morphology of fine precipitatates, (c) EDS results of the precipitate in (b)

\footnotetext{
a Corresponding author: hengchengliao@seu.edu.cn
} 

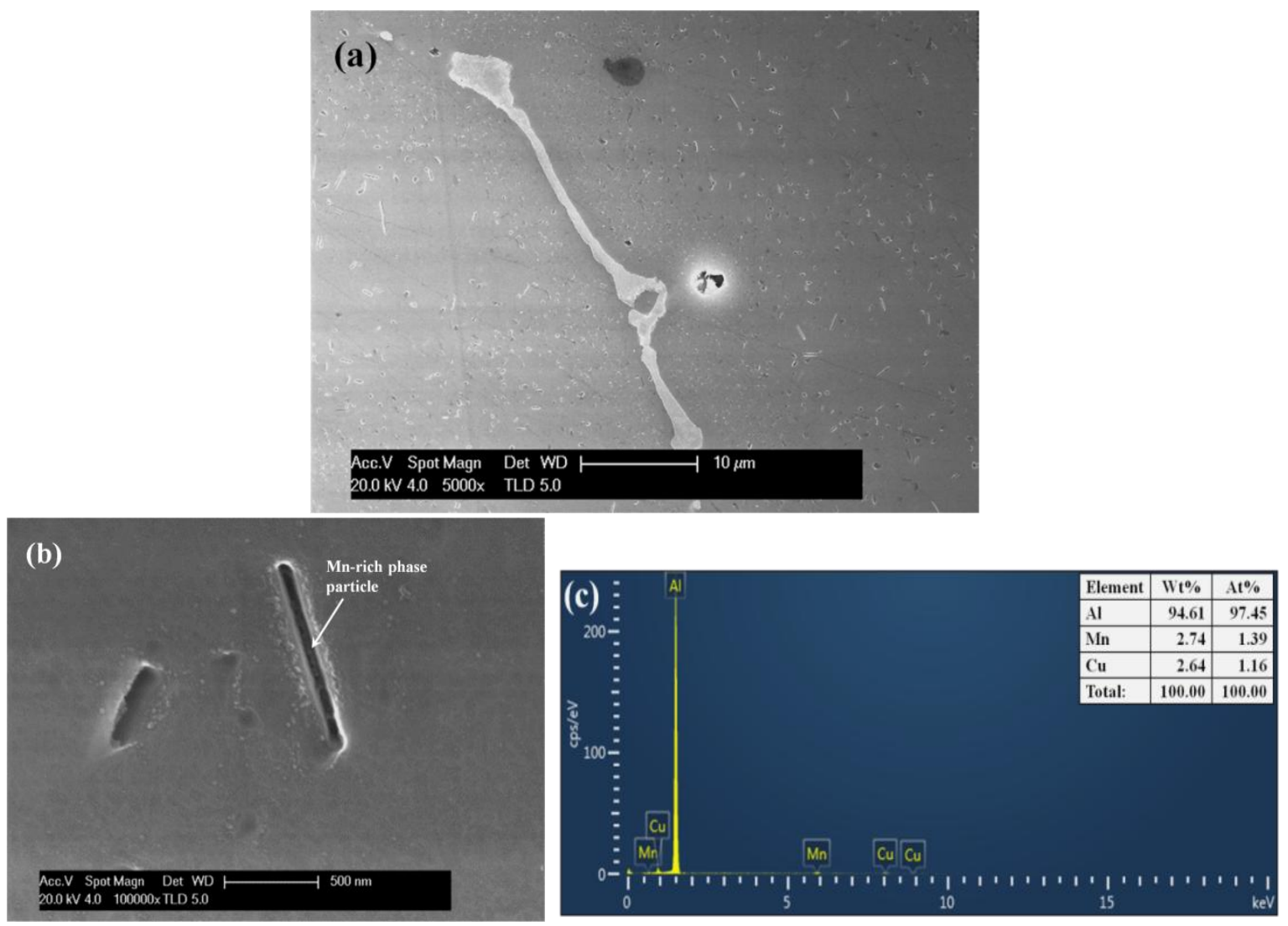

Figure 6: SEM micrographs of Alloy-2 after solution treatment $\left(530^{\circ} \mathrm{C}\right.$ for $\left.16 \mathrm{hrs}\right)$, (a) a great amount of precipitates adjacent to interdendritic region, (b) morphology of fine precipitatates, (c) EDS results of the precipitates in (b)

\subsection{Mechanical properties}

Results of tensile properties of Alloy-1 and Alloy-2, at different temperature, are summarized in Table 2. It shows that Alloy-1 has low value of yield strength i.e. $44 \mathrm{MPa}$ at room temperature when compared to that of Alloy-2 i.e. 66MPa. Similar trend is observed in ultimate tensile strength of both the alloys. However, Alloy-1 has experienced higher plastic deformation prior to failure due to low amount of $\mathrm{Cu} \& \mathrm{Mn}$ contents and Alloy-2 has experienced lower plastic deformation. High temperature tensile test is carried out at $300^{\circ} \mathrm{C}$. Results of these tests representing the mechanical behavior of Alloy-1 and Alloy-2 are shown in Figure 7(a) and (b), respectively. It is observed that the ultimate tensile strength of Alloy-1 is dropped from $120 \mathrm{MPa}$ to $48 \mathrm{MPa}$ and the elongation is increased significantly from $37 \%$ to $56 \%$. It is considered to be because of dissolution and/or coarsening of the precipitates at high temperature. While the ultimate tensile strength of Alloy-2 decreases to $82 \mathrm{MPa}$ and elongation increases from $23 \%$ at room temperature to $37 \%$ at $300^{\circ} \mathrm{C}$. It is clear that the ultimate tensile strength of Alloy 2 is much higher than that of Alloy 1 and it also experiences less plastic deformation. This behavior of Alloy-2 is attributed to the presence of Mn-rich (T-phase) particles within the grain interiors hindering plastic deformation at high temperature. These results are in agreement with literature suggesting that Mn-rich (Tphase) particles can improve high temperature properties by impeding the grain boundary movement[11].
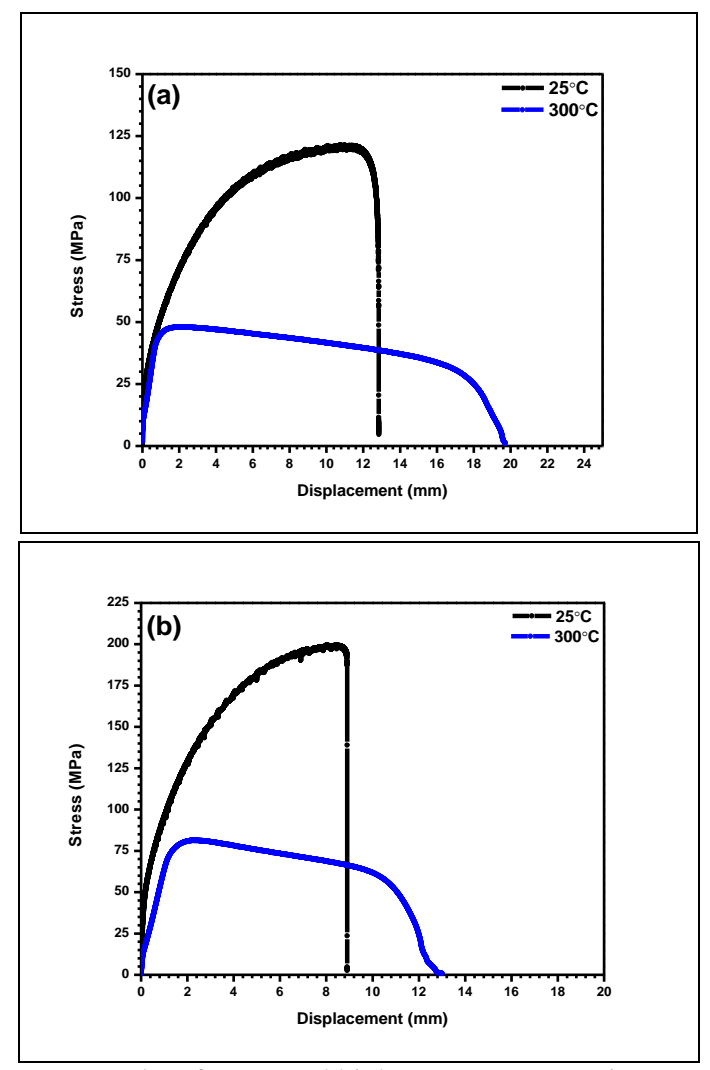

Figure 7: Results of room and high temperature tension experiment, (a) Alloy-1 and (b) Alloy-2 
Table 2: Mechanical properties of experimental alloys at $25^{\circ} \mathrm{C}$ and $300^{\circ} \mathrm{C}$

\begin{tabular}{ccccc}
\hline $\begin{array}{c}\text { Alloy } \\
\text { Name }\end{array}$ & Temp. & $\begin{array}{c}\text { YS } \\
(\mathrm{MPa})\end{array}$ & $\begin{array}{c}\text { UTS } \\
(\mathrm{MPa})\end{array}$ & Elong. \\
\hline Alloy-1 & \multirow{2}{*}{$25^{\circ} \mathrm{C}$} & 44 & 120 & $37 \%$ \\
Alloy-2 & & 66 & 199 & $23 \%$ \\
\hline Alloy-1 & \multirow{2}{*}{$300^{\circ} \mathrm{C}$} & - & 48 & $56 \%$ \\
Alloy-2 & & - & 82 & $37 \%$ \\
\hline
\end{tabular}

\section{Conclusions}

(1) As-cast microstructure of both the alloys (with varying $\mathrm{Cu} / \mathrm{Mn}$ content ratio) consists of trunks of $\alpha$-Al dendrites and interdendritic $\mathrm{Cu}$-rich regions where $\theta$ $\mathrm{A} 12 \mathrm{Cu}$ particles are formed. No ternary (Al-Cu-Mn) intermetallics are observed

(2) After solution treatment, a great amount of precipitates are found to form adjacent to the $\mathrm{Cu}$-rich regions, most $\mathrm{CuAl}_{2}$ particles in Alloy-1 and most Tphase(Al-Cu-Mn intermetallic compound) in Alloy-2

(3) Alloy-2 with low $\mathrm{Cu} / \mathrm{Mn}$ content ratio exhibits high strength due to higher thermal stability and much greater amount of $\mathrm{T}$-phase particles

\section{References}

1. X.W. Yang, J.C. Zhu, Z.S. Nong, M. Ye, Z.H. Lai, and Y. Liu, Modern Physics Letters B, 27, 13410361-13410368 (2013).

2. A.R. Toleuova, N.A. Belov, D.U. Smagulov and A.N. Alabin, Metal Science and Heat Treatment, 54, 27-31 (2012).

3. L. Fan, Q.T. Hao, and W.K. Han, Rare Metals, 34, 308-313 (2014).

4. Z.W. Chen, M.J. Tang, and K. Zhao, International Journal of Minerals, Metallurgy, and Materials, 21, 155-161 (2014).

5. Z.W. Chen, P. Chen, and S.S. Li, Materials Science and Engineering: A, 532, 606-609 (2012).

6. Z.W. Chen, P. Chen, and C.Y. Ma, Rare Metals, 31, 332-335 (2012).

7. N.A. Belov, A.N. Alabin, and I.A. Matveeva, Journal of Alloys and Compounds, 583, 206-213 (2014).

8. A.S. Prosviryakov, K.D. Shcherbachev, and N.Y. Tabachkova, Materials Science and Engineering: A, 623, 109-113 (2015).

9. L.F. Mondolfo, Aluminum Alloys: Structures and Properties, Butterworth and Co (Publishers) Ltd, 310 (1976).

10. N.A. Belov, D.G. Eskin, and A.A. Aksenov, Multicomponent Phase Diagrams, Elsevier: Oxford, 159-192 (2005).

11. Y.Q. Chen, D.Q. Yi, Y. Jiang, B. Wang, D.Z. Xu, S.C. Li, Journal of Material Science, 48, 32253231(2013) 